\title{
Introduction to HICCS-55 Minitrack on Digital and Social Media in Enterprise
}

\author{
Tawei (David) Wang \\ DePaul University \\ david.wang@depaul.edu
}

\author{
Ester S. Gonzalez \\ California State University \\ Fullerton \\ esgonzalez@fullerton.edu
}

\author{
Xuefei (Nancy) Deng \\ California State University \\ Dominguez Hills \\ ndeng@csudh.edu
}

\section{Introduction}

Digital and social media (DSM) have transformed the workplace in organizations. Two decades ago, electronic communication changed organizational forms, enabled electronic document management, and preserved organizational memory. During the past two decades, the growth of digital and social media technologies has impacted organizations in new ways. Social media includes blogs, wikis, social networking sites, and microblogging that provide new affordances to its users. While some prior studies have provided evidence to show the positive impacts of enterprise social media on employees, work processes and performance, other studies have uncovered negative effects of DSM use on employee productivity and behaviors. Since spring 2020, the global outbreak of the coronavirus (COVID-19) pandemic has increased social media use in home offices when companies sent employees to work from home to contain the spread of the deadly virus. For an organization to amplify the returns or benefits and to mitigate the drawbacks of their DSM use, it is imperative for both researchers and practitioners to deepen their understanding of the implications of DSM use for organizational purposes.

\section{Scope}

This minitrack focuses on the internal and external use of digital and social media by organizations to facilitate work processes (e.g., communication, collaboration, innovation and socialization) inclusive of business, non-profit organizations, and government agencies. Hence, research of this minitrack lies at the intersection of multiple disciplines, namely Science \& Technology, Organization Science, Marketing, and Behavioral Science.

This minitrack presents both theoretical and empirical studies addressing organizational, managerial, technical, and behavioral perspectives on digital and social media in enterprises.

Potential issues and topics include, but are not limited to:

- Digital and social media affordances

- Digitization of work and its impact on work process

- Dark side of enterprise social media

- Digital and social media use \& employee work-life balance

- Digital and social media use \& Information security

- Enterprise social media use during the COVID-19 pandemic

- Effects (both positive and negative) of digital and social media at workplace

- Methodologies for studying digital and social media in enterprise

- Organizational management practices associated with digital and social media use

- New theories to describe and explain the phenomenon of using digital and social media in workplace

- Roles and responsibilities of IS departments in the use of and support for digital and social media

- The use of social media \& fundraising or donations

- $\quad$ The use of social media \& public perception management

- The use of social media \& enterprise strategy

\section{Summary of Articles}

This mini-track presents three papers in HICCS55. We introduce them briefly below.

Enterprise social networks have been discussed to demonstrate how they can facilitate knowledge sharing and team management, but it is still unclear 
how organizations can identify the value-adding users in the network. Though the notion of value has been defined differently in different contexts, Schmid, Wehner, and Leist [1] summarize prior literature and propose the use of the following dimensions to identify these value-added users: network structure, message, behavior, and social network affinity. A case study was later performed by using an international consulting company's enterprise social network platform. The authors were able to use the company's network to demonstrate how these dimensions can be used to find valueadded users for sharing knowledge and providing real-time feedback. These measures can also affect employee behaviors while achieving the organizations' goals.

From an opposite perspective, Guan, Hsu and $\mathrm{Xu}$ [2] focus on employee's deviant behaviors on social media. These behaviors can go viral fast and negatively affect the organization. Different from prior literature about social media deviance that focuses on inappropriate social media usage behaviors, the authors focus more on the motivations to these behaviors. Building on the psychological contract breach theoretical perspective, the authors examine and demonstrate that employees who experience abusive supervision (i.e., hostile verbal and nonverbal behaviors) are more likely to perceive psychological contract breach. Such perception can lead to social media deviant behaviors. In order to reduce such positive relationship, the awareness of social media policy and informal sanctions can play an important role.

Finally, Scherer et al. [3] rely on visual analysis to help organizations better monitor their branding presence on social media. The proposed techniques in the paper can be used to understand public perception, attention (both good and bad), and commenting activities. The authors propose a dashboard that includes six different pieces of information including post list, total number of positive, neutral and negative comments, rank of most liked comments, number of positive neutral and negative comments over time, word clouds for both positive and negative comments. Two cases regarding Netflix and Amazon Prime Video are applied to demonstrate the usefulness of the proposed techniques.

The presentations of the three papers covers a wide range of topics from benefits, challenges to specific techniques, which enhance our understanding about the role, use and implications of enterprise social media.
[1] Schmid, I., B. Wehner, and S. Leist. Identifying valueadded users in enterprise social networks. in HICSS-55 Proceedings, January 3-7, 2022, virtual conference.

[2] Guan, B., C. Hsu, and F. Xu. Examining employee social media deviance: A psychological contract breach perspective. in HICSS-55 Proceedings, January 3-7, 2022, virtual conference.

[3] Scherer, J. P., P. H. M. Sanvido, M. S. Silveira, and I. H. Manssour. Integrated visual analysis for brand perception on different social networks. in HICSS-55 Proceedings, January 3-7, 2022, virtual conference.

\section{References}

